\title{
The Role of Pronunciation in the Competency-based English Curricula of Algerian Middle and Secondary Schools
}

\begin{abstract}
:
The present study attempts to explore the degree of compatibility between middle and secondary school teachers' practices in the teaching and assessment of pronunciation and the principles of Competency-Based Language Teaching. To achieve this goal, two questionnaires have been designed and implemented to 87 middle and 62 secondary school teachers. In addition, a representative sample of official exams at both levels has been analysed. The analysis of the results revealed that the existence of a big discrepancy between pronunciation teaching and assessment practices of the respondents at both levels and the principles of competency-based language teaching.
\end{abstract}

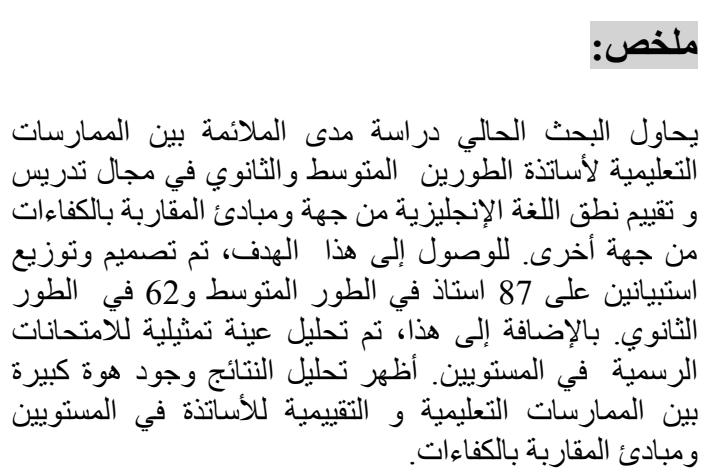

(c) Université des Frères Mentouri Constantine1, Algérie, 2018.

\section{Zahia bouchair}

Département des Lettres et Langue Anglaise

Université des Frères Mentouri Constantine

\section{Introduction :}

Pronunciation is an important and integral part of language and, thus, a key component of successful communication.

Developing

effective communicative competence necessitates the development of an adequate level of pronunciation skills. The teaching of pronunciation, however, has until recently been neglected by different language teaching methodologies. 
In spite of the recognition and integration of this essential language component in modern teaching methodologies like competency-based language teaching, the effectiveness of instruction in this regard remains a real point of concern for syllabus designers and practitioners alike especially in a foreign language context like ours.

\section{Statement of the Problem}

Effective communication in English or any other language is not possible if language users' pronunciation is poor no matter how strong and elaborated is their command of grammar and vocabulary. The need for adequate levels of pronunciation has been accentuated in today's increasingly globalized world marked by the rise of English as a linguafranca and the unprecedented widespread and extensive use of online communication using information technology. Brinton (2012: 255) rightly points out that "in the world of ELT today, pronunciation has come to be rightfully recognised as a critical skill".

In the Algerian context, after being neglected in the communicative English language syllabi of middle and secondary schools in the 1980s and 1990s, the status of pronunciation has changed thanks to the introduction of the competency-based curricula starting from 2003. The competency-based approach, which aims at providing learners with better quality education and coping with the increasing demands of the new millennium, emphasises the practical use of language in real life situations. For this reason, pronunciation occupies a crucial position due to the key role it plays in fostering learners' interactive, interpretive and productive abilities.

Several years of experience in teaching the subject of English Phonetics and Phonology at the tertiary level to a large number of students who are the by-product of these reforms have provided us with sufficient first hand evidence that the overriding majority of these students fail to achieve a threshold level of intelligibility in the pronunciation of English. Normally, after seven years of instruction in English pronunciation following a competency-based methodology, which is especially geared towards increasing the transferability of the skills acquired in the classroom to real life situations, Algerian learners of English are supposed to be able to demonstrate, at least, an intelligible level of pronunciation in this foreign language. This anomalous situation has aroused our curiosity to explore the real causes of this 
failure. More specifically, the present study aims at determining, as far as pronunciation is concerned, whether the observed failure is due to the inadequacy of the approach itself or rather to the discrepancy in its implementation.

In the light of what has been said above, the present study seeks to answer the following three major questions:

1. Are the teachers' pronunciation instructional practices compatible with the principles of competency-based language teaching?

2. Are the teachers' pronunciation assessment practices compatible with the principles of competency-based language teaching?

3. Are the teachers' assessment practices compatible with the design of official examinations?

\section{Review of the Literature}

Pronunciation is generally defined in relation to its components, which are classified into three major components: segmental, suprasegmental features and aspects of connected speech (Roach, 2000; Kenworthy, 1987; Dalton and Seilhofer, 1994). At the segmental level, three types of sounds are identified: vowels, diphthongs, and consonants (Kenworthy, 1987). The suprasegmental aspects, sometimes referred to as prosodic features, include stress, rhythm and intonation (Ladefoged, 2001). The third aspect, which is mainly concerned with the changes that occur to sounds when they combine in larger units, includes, but is not limited to, assimilation, elision and liaison (Roach, 2000). Pronunciation is also defined by distinguishing it from phonology as the two terms are often used interchangeably. According to Burgess and Spencer (2000: 191-192), while phonology "consists of theory and knowledge about how the sound system of the target language works, including both segmental and suprasegmental features", pronunciation is "the practice and meaningful use of TL phonological features in speaking, supported by practice in interpreting those phonological features in TL discourse that one hears". Knowledge of English phonology is certainly beneficial to the learners because awareness about the role and significance of the phonological features enables them to process language messages appropriately both receptively and productively.

\subsection{The Place of Pronunciation in Language Teaching Methodology}


The importance of pronunciation has been highlighted by many authorities in the field of English language teaching. Tench (1981), for example, points out that pronunciation is as important as grammar or vocabulary and that speech is impossible without an adequate level of pronunciation. In the same vein, Tarone \& Yule (1989) stress that it is impossible for a language learner to be proficient in a language without developing a certain level of grammatical competence, including the pronunciation aspect. The importance of pronunciation is also discussed in relation to improving listening comprehension as the latter is improved by an awareness of the pronunciation features (Pennington, 1996 and Harmer, 2001).

Despite its unquestionable importance, however, pronunciation has been marginalised for a long time in English language teaching. Indeed, the role of pronunciation in language teaching has witnessed many swings of the pendulum in different approaches and methods (Celce Murcia, 1987; Morley, 1991; Celce Murcia, et al.; 1996, Celce Murcia et al., 2010). While pronunciation was viewed irrelevant or unimportant in the Grammar Translation Method, the Reading Approach, Suggestopedia, Total Physical Response and the Natural Approach, it was emphasized, though with varying degrees, in the Direct Method, the Audio-lingual Method, Situational Language Teaching, the Silent Way and Community Language Learning. Surprisingly, in the early years of the Communicative Approach, during the transition from linguistic competence to communicative competence, pronunciation was neglected (Knowles, 1995; Jones, 1997; Murphy, 1991) because it was believed that the learners improve their pronunciation unconsciously through mere exposure to the target language comprehensive input. However, when the approaches emanating from the communicative philosophy reached a certain level of maturity, pronunciation was acknowledged as an essential element to achieve communication, the core of the communicative approach (Celce-Murcia et al., 1996).

2.2. The Practice of Pronunciation Teaching in English as a Foreign Language Context

The context or the setting variables play an important role in pronunciation instruction. Indeed, an important issue that has to be settled prior to incorporating pronunciation into the curriculum is the specification of the setting variables. The latter are concerned with constraints emanating from the general context in which a language 
syllabus is being implemented (Celce-Murcia et al., 1996). In this regard, a distinction is generally set between a foreign language setting and a second language setting. Unlike the latter where the learners are extensively exposed to the target language, in the former, the learners' exposure to native- like model of pronunciation is often limited as most, if not all, teachers are non-native speakers. The rise of English as a lingua-franca led Celce-Murcia et al.,(2010) to add yet another distinction, the English as an International Language setting, which differs from the two traditional settings in the sense that then, English came to be considered as a major means of communication in international contexts, not only between non-native speakers and native speakers but also between non-native speakers and other non-native speakers ( Jenkins, 2000).

Another important issue regarding the teaching of pronunciation concerns the way of its integration in the language syllabus. As far as the specification of the goals is concerned, current pronunciation research has shown that intelligibility, defined by Kenworthy (1987: 13) as "being understood by a listener at a given time in a given situation", is regarded as a more reliable goal (Jenkins, 2000; Derwing and Munro 2005; Celce-Murcia et al. 2010). In line with this new conception, pronunciation should not be an end in itself, but, instead, should be regarded as a means that helps achieve communicative ability (Dalton and Seidhofer, 1994). In addition, pronunciation instruction should respond to the learners' needs by focusing on the common pronunciation problems or the anticipated difficulties in order to avoid or at least to minimise the effects of the first language (Kenworthy, 1987; CelceMurcia et al. 2010) or any other language learnt before the target language. After setting the goals, selecting the appropriate content is the second major step. In this regard, evidence has shown that pronunciation researchers and practitioners favour a more balanced approach that equally incorporates segmentals and suprasegmentals, highlights the pronunciation/spelling relationship and focuses on both perception and production of intelligible pronunciation features (Kenworthy, 1987; Morley, 1991; Celce-Murcia et al. 2010). Once the content is selected and sequenced appropriately, it is of crucial importance to opt for adequate methodology. Research recommends incorporating both deductive and inductive modes of practice, using a variety of techniques in order to account for different learning styles, focusing on the 
relationship between listening and pronunciation, integrating pronunciation with the learning of other language learning practice and promoting autonomous pronunciation learning (Morley, 1991).

The factors determining EFL pronunciation instruction should also be taken into consideration during the process of its incorporation in a language syllabus. Based on Celce Murcia et al. (1996) and Celce Murcia et al. (2010), these factors can be divided into the teaching context, learner-related factors and teacher-related factors. Firstly, the EFL teaching context includes such factors as national language policy, teacher preparation, curriculum materials and teaching and learning resources. Of particular importance is the size of language classes and the role of examinations. Secondly, the learner-related factors include the learners' age, proficiency level, linguistic and cultural background, prior exposure to the target language, amount and type of prior pronunciation instruction, language aptitude, learning style, previous exposure to a second language, attitude toward the target language and motivation to achieve adequate pronunciation. Thirdly, the teacherrelated factors encompass teachers' attitudes and teachers' knowledge and training, quality of teachers' English pronunciation and teachers' involvement in instruction.

\subsection{The Challenges of Teaching Pronunciation in Algeria}

The Algerian context is characterised by a complex linguistic situation where a number languages and language varieties come into play, which, hence, represent the first major challenge to the syllabus designer as far as English pronunciation is concerned. While Algerian Arabic is the mother tongue of the majority of the population and Tamazight is the mother tongue of the Berber population, Standard Arabic, which has no mother tongue speakers, is the official language. French, the language of the former colonizer, is considered officially as the first foreign language, but this language still enjoys a special status and some, at least, consider it as their second language. Given that negative transfer from the mother tongue is considered as a major problem to learners of English pronunciation, the Algerian syllabus designers face a real dilemma when it comes to the choice of which mother tongue to focus on when deciding about the degree of difficulty of the different aspects of pronunciation to the one-fits-all syllabus they are supposed to design. 
Moreover, the special status of French also poses a serious problem. In the current Algerian school system, based on 5+4+3 model (five, four and three years of primary middle and secondary education, respectively), French is introduced as the first foreign language in the third grade of primary education and English is introduced as the second foreign language in the first year middle school when the learners are aged 11-12. This means that English is introduced three years after French. It is worth mentioning that Algerian pupils are familiar with some French before studying it as a subject due to the social status it plays and also the fact that Algerian Arabic encompasses some French.

Generally speaking, the pronunciation difficulties or problems facing the Algerian learners of English can be grouped into two main categories: interlingual problems and intralingual ones. The former are specific to the Algerian learners who tend to be classified in Error Analysis studies sometimes among the 'speakers of Arabic type and sometimes among the 'speakers of French type (Beghoul, 1984 cited in Beghoul 2007). However, Beghoul's study (2007) has shown that the Algerian learners involved in the error analysis have linguistic, educational, and cultural backgrounds that are, somehow, mixtures of Arabic and French. He also ascertains that in pronunciation instruction, French has an influence on the acquisition of English pronunciation in the Algerian context. Accordingly, the interlingual problems can further be divided into two groups: problems due to the influence of French and problems due to the influence of Arabic. The intra-lingual difficulties emanate mainly from the complexity of the English pronunciation and spelling systems. Based on Kenworthy ( 1987), Swan and Smith (1987, cited in Beghoul 2007), Rogerson Revell (2011), Kelly ( 2000, cited in Beghoul 2007) and Beghoul ( 2007) and taking into account the linguistic background of Algerians and the status of English as a foreign language, a number of pronunciation priorities is considered essential for Algerian learners:

Sound/ spelling relationship: most of the pronunciation errors made by Algerian learners are not articulatory in nature but they are due to the discrepancies between pronunciation and spelling.

Segmental priorities: Schwa, mid and open vowels / e /- /æ $/-/ \Lambda /$, diphthongs and consonants / $\mathrm{y} /, / \mathrm{r} / / \mathrm{t} \mathrm{J} / / \mathrm{d} z /$

Suprasegmental priorities : word stress, sentence stress and rhythm and intonation 
Aspects of connected speech (only for perception purposes)

2.4. Competency-Based Language Teaching and Pronunciation Teaching in Algeria

When it was first introduced in the Algerian educational system in 2003, the competency-based approach (CBA) was embraced as a new concept and has become a buzz word not only in the field of English but in all fields of study and in the different levels of educational system. However, the pedagogic principles upon which CBA is based can be traced to the 1970s and have been introduced in education for more than 4 decades in the developed countries (the United States of America, Canada, United Kingdom and Australia).

\subsubsection{An overview of the Competency-Based Approach}

The CBA emerged to respond to the urgent needs of immigrants who needed to survive and to work in target language communities (Graves, 2001; Richards and Rodgers, 2001) and, accordingly, the CBA has been associated with vocational-related and survival oriented programs in ESL education (Richards and Rodgers, 2001). Noticeable in the literature on the CBA is the use of a host of names and labels that are used synonymously with the CBA or to refer to programs based on the CBA such as competency based education, competency based instruction, competency based programs, competency based models, competency based frameworks and sometimes, it is even used interchangeably with competency based training.

At present, the CBA is an issue which is much discussed as many countries, developed and developing, from different parts of the world, are implementing competency based curriculums. In this regard, Richards (2015: 79) comments that "recently, competency-based frameworks have become adopted in many countries, particularly for vocational and technical education" and that "they are also increasingly being adopted in national language curriculums". The rationale behind adopting such an approach is to improve the quality of education. Evidence has shown that it is not sufficient to master some amount of knowledge and to have a command of skills to function successfully in educational, social or professional settings. So, the CBA, characterised mostly by a shift in focus from acquiring knowledge and skills to the ability to use them, enables the learners to act successfully in new 
problematic situations inside as well as outside the classroom as the CBA stresses the link between learning carried out at school and everyday life.

Throughout its evolution, the CBA has been conceptualised differently. The literature suggests that there are different versions of the CBA that share many similarities and principles. Our review of the literature, both at the national and the international levels, revealed that there is a widespread uncertainty as to what exactly the CBA involves, what it means in theory and in practice. However, the two influential versions are the Anglo-Saxon version and the one adopted in Francophone countries (French speaking Belgium and Switzerland, France and Quebec) and many African countries (Tunisia, Algeria, Morocco, Mali, Niger, Mauritania, Cameroon, Tanzania, Ghana, Rwanda, Madagascar...etc.). However, it is worth noting that despite the fact that these countries adopted the CBA, each one of them has interpreted and implemented the approach in its own way.

Nonetheless, there is a general consensus that the CBA emerged as a reaction to the ineffectiveness of the objectives based pedagogy in fostering learners' thinking skills and autonomy in the 1970s in developed countries (Lenoir and Jean, 2012). According to them, this approach, which has strongly been criticised in the 1970s, "has widely been abandoned in favor of what is commonly referred to as the competency based approach" (2012: 68). The latter was adopted in developed countries since the 1970s and 1980s. Nonetheless, it was not until the beginning of the new millennium that African countries, including Algeria, opted for the implementation of the CBA, which was considered as "the magic solution" to foster quality education.

Additionally, the CBA has been related to different approaches. First, because the CBA stresses the learners' performance, it has been used synonymously with performance-based learning (Bowden, 2004). In this regard, competency-based education is defined by The United States Office of Education as "a performance-based process leading to demonstrated mastery of basic and life skills necessary for the individual to function proficiently in society" (Quoted in Savage, 1993: 556). An example of a competency based model focusing on the learners' performance is the Common European Framework of Reference. The latter, which specifies the performance levels that need to be achieved by European students in order to satisfy the European Union educational 
and professional standards, describes learning outcomes in terms of competencies (Richards, 2015). Second, the CBA is also regarded as a type of Outcome based Education because it emphasizes what the learners are expected to perform after instruction. Third, the CBA also supports the concept of mastery learning (Harris et al. 1996). Assessment lies at the heart of the CBA; it is regarded as an integral part of the process of the development of competencies. So, like mastery learning which emphasises that a learner attends to "a learning process until the learner demonstrates proficiency in the stated outcomes" (Harris et al. 1996: 138), the CBA encourages the pre-test - teach - test - reteach pedagogy, the essence of Mastery Learning.

2.4.2. The Implementation of the Competency-Based Approach in Algeria

In Algeria, the CBA has been introduced in 2003 as a replacement of the objectives based pedagogy which had dominated teaching for more than two decades. As expressed in the Algerian official syllabuses, the CBA seeks to help the learners act in real-world contexts effectively and, so, it emphasises the link between what students learn in school and everyday uses of the language. To put the CBA into practice, the Pedagogy of Integration is adopted as the methodological framework, not only in Algeria but in many other Francophone countries. According to Roegiers and De Ketele (2000), the pedagogy of integration, a methodological framework to put into practice a curriculum policy, aims at enabling the learner to solve a complex problem situation by mobilising a set of resources acquired during actual learning.

In fact, the concept of 'competence', the core of the CBA, is defined in the Algerian official documents as "a known how-to-act process which integrates a set of capacities, skills, and knowledge mobilized to face problem- situations" (Ameziane, 2005:12). Hence, these have adopted the same definition of the term competence provided by Roegiers (2000) and Tardif (2003), in which the terms integration, mobilisation and problem situations are highlighted. So, instead of transmitting knowledge directly to passive learners, the latter are placed in front of problem situations to reflect on by mobilising a set of resources, consisting of knowledge, skills and attitudes, to solve the problem. Because the $\mathrm{CBA}$ is a constructivist approach the learners are 
urged to activate their previously acquired knowledge and skills to construct new ones. In addition, one of the main principles of the CBA is the transfer of knowledge from a situation to a new one inside or outside the classroom. Therefore, it is of paramount importance for the learners to become aware of the resources they have and how to re-invest them in solving problem-situations they may face inside or outside school. Furthermore, it is clearly stated in the syllabuses that the CBA is characterised by a learner-centred approach to teaching and learning and that it seeks to develop autonomous learners, capable of taking charge of their own learning. Accordingly, the learners are encouraged to be active participants in the process: they learn how to learn, they learn by doing, they learn to construct their knowledge and they take responsibility for their own learning.

With regards to language teaching, where a competency based approach is adopted, the term Competency-based Language teaching (CBLT) is widely used. According to Richards and Rodgers (2001, 2014), CBLT is the application of the principles of the CBA to language teaching. CBLT has been designed to improve the quality of students' achievement in the target language and develop their communicative competence. In order to realise this aim, the CBA principles and features must be focused on from planning to the implementation phase.

CBLT shares many characteristics with Communicative Language Teaching (CLT), that is why Richards and Rodgers (2001) consider it as an extension of CLT. In fact, in their seminal work on approaches and methods in language teaching, they classified CBLT as an outcome based communicative approach. One of the major features of CBLT is that the ultimate goal is achieving communicative ability as in CLT. Moreover, Graves (2001: 185) stresses the fact that CBLT is "a combination of the communicative and task-based approaches and has been used in courses for teaching immigrants, who have immediate needs with respect to functioning in the community and in the workplace".

Auerbach (1986, cited in Richards and Rodgers 2001, 2014) provides eight features that are involved in the implementation of competency-based education programs in language teaching:

1. A focus on successful functioning in society: the goal is to enable students to become autonomous individuals capable of coping with the demands of the world. 
2. A focus on life skills: rather than teaching language in isolation, CBLT teaches language as a function of communication about concrete tasks. Students are taught just those language forms/ skills required by the situations in which they will function.

3. Task- or performance-oriented instruction: what counts is what students can do as a result of instruction. The emphasis is on overt behaviours rather than on knowledge or the ability to talk about language and skills.

4. Modularized instruction: language learning is broken down into meaningful chunks. Objectives are broken into narrowly focused subobjectives so that both teachers and students can get a clear sense of progress.

5. The explicit statement of outcomes: outcomes are public knowledge, known and agreed upon by both learner and teacher. They are specified in terms of behavioural objectives so that students know what behaviours are expected of them.

6. Continuous and ongoing assessment: Students are pre-tested to determine what skills they lack and post-tested after instruction on that skill. If they do not achieve the desired level of mastery, they continue to work on the objective and are retested.

7. Demonstrated mastery of performance objectives. Rather than the traditional paper-and-pencil tests, assessment is based on the ability to demonstrate pre-specified behaviours.

8. Individualized, student-centred instruction. In content, level, and pace, objectives are defined in terms of individual needs; prior learning and achievement are taken into account in developing curricula. Instruction is not time-based; students progress at their own rates and concentrate on just those areas in which they lack competence.

Recently, Richards (2015: 79) highlighted that these "eight features which are involved in the implementation of CBLT programmes in language teaching, in its early days... are true of many such programmes today".

In fact, many of these principles are implicitly or explicitly reflected in the Algerian English syllabuses. First, it is clearly stated that the goal of English teaching is to enable the learners to develop communicative ability. This means that teachers should focus their attention on language as a tool for communication rather than on language knowledge as an end in itself. Second, individualised 
instruction and learner-centeredness are highlighted, explicitly and also implicitly by emphasising the importance of developing learner strategies and different styles of teaching including individual as well as collective teaching, as the most appropriate methodology. Third, fostering learner autonomy is also one of the highlighted principles. It is clearly stated in the syllabuses that the goal of teaching is to produce autonomous learners. Fourth, diagnostic assessment is also considered. The teachers are required to diagnose what the leaners already have and what they lack. So, diagnostic assessment is considered the proper starting point for helping the learner achieve the set of competencies. Fifth, matching with the principles of the CBA is the introduction of formative assessment, consisting mainly of continuous assessment practices. The latter needs to be incorporated and thoroughly implemented by teachers. Moreover, self-assessment, regarded a way of giving the pupils a feeling of responsibility for their learning is integrated in the different textbooks through the use of self-assessment questionnaires or grids requiring the students to evaluate their acquisitions that are directly linked to course content and objectives. In addition to the previously mentioned principles, integration or mobilisation, derived from the pedagogy of integration, is of utmost importance as the competency based approach in Algeria is equated with the pedagogy of integration.

2.4.3. Pronunciation Teaching and Assessment within the Framework of CBLT

The review of the literature on the CBA and the pedagogy of integration and more specifically of the principles of CBLT, which is considered as an extension of communicative language teaching on the one hand and the examination of the current perspectives in pronunciation instruction on the other hand revealed that it is possible to establish a link between pronunciation instruction and CBLT. Interestingly, it is found that most of the current perspectives of pronunciation instruction can be aligned with CBLT principles.

Arguably, incorporating pronunciation in a CBLT model aiming at developing the learners' ability to communicate in the language is a necessity. The CBA focuses on developing the learners' competencies to function successfully in society and stresses the link between language as it is taught in class and as it is used in real life 
situations. In CBLT, the ultimate goal is to enable the learners to achieve communicative competence by focusing on realistic English, of which pronunciation is an indispensable component. The Common European Framework of Reference, which describes what the learners "have to learn to do in order to use language for communication and what knowledge and skills they have to develop so as to be able to act effectively" (Council of Europe, 2001:1) acknowledges the vital role of pronunciation within a general foreign language competence. In fact, phonological control is highlighted as one of the sub-competences of linguistic competence, which, in turn, is considered, together with sociolinguistic and pragmatic competences as the three main components of communicative language competences. Because pronunciation is an indispensable component of achieving communicative competence, it needs to be incorporated in CBLT classes, especially in the era of English as a Lingua France, where the major goal of instruction is enabling the learners become competent listeners, speakers, readers and writers of the language.

The goal of pronunciation instruction in a CBLT model should be developing learners' communicative ability. More specifically, instead of teaching pronunciation for the sake of pronunciation, it should be taught for communication purposes. Since CBLT falls within the umbrella of the communicative approach and since its main goal is to develop the learners' communicative activity, pronunciation should be taught within a communicative framework. In other words, in order to communicate effectively, adequate pronunciation is required and in order to enable the learners develop their pronunciation skills, pronunciation should be taught in a communicative way.

As far as the methodology is concerned, pronunciation should be taught in a CBLT model through the rigorous application of the CBLT principles encompassing mainly the following pedagogic features: fostering learner autonomy, integration/ mobilisation, individualized instruction/ student-centred instruction, diagnostic assessment, formative assessment/self-assessment and demonstrated mastery of performance objectives. When applied appropriately to this aspect, the learners are enabled to achieve the pronunciation competency. Hence, in order to empower the learners' pronunciation competency in a course which is competency-based, effective pronunciation instruction should fulfil the following criteria: 
Learner autonomy criteria: the learners in a CBLT model should be enabled to learn and improve their pronunciation independently. This can be realised through developing appropriate pronunciation learning strategies and experiences such as phonetic notation (and other forms of visual reinforcement) and self- correction strategies.

Integration/mobilisation criteria: in CBLT, the learners are required to integrate or to mobilise a set of resources, of which pronunciation is one of them, to solve a communicative task or problem. In other words, the learners should integrate or apply the phonological knowledge acquire in pronunciation activities in communication tasks. This can be realised through encouraging the learners to integrate continuously the pronunciation elements taught in their speech, including the projects. In other words, it is important to make the learners reinvest constantly their knowledge in new communicative situations.

Individualised instruction/student-centred instruction: in order to make the objectives attainable in CBLT, it is crucial to stress individualised instruction/ student-centred instruction. This can be realised by varying the types of activities to account for variation in the nature of the students' aptitude and learning styles, adopting a flexible teaching approach: the teacher varies his/her teaching strategies to fit the learners' ones, catering for slow or less able learners, involving learners by making them participate, providing them with sufficient practice inside and, if necessary, outside the classroom, involving them in pair and group work activities and by taking the learners' needs into consideration, especially by focusing on high pronunciation priorities.

Diagnostic assessment criteria: it is necessary to assess the learners' pronunciation at the beginning of a course and automatically respond to the learners' results before and also during instruction to remedy for the weaknesses.

Formative Assessment/self-assessment criteria: it is necessary to assess learners on a regular basis to gauge if the students have achieved the pronunciation competency, to provide them with feedback, selfcorrection strategies, and peer correction and also to give the learners the opportunity to reflect on their pronunciation learning.

A further point worth considering in investigating the role of pronunciation in CBLT is the most appropriate way of testing it. One major principle of CBLT is demonstrated mastery of performance objectives. In connection with pronunciation, effective pronunciation 
instruction must ensure that the learners achieve adequate pronunciation skills. For this end, pronunciation should be tested through oral tests that genuinely measure pronunciation performance and not just pronunciation knowledge. In this regard, Allison (1999) argues that rather than using separate tests of knowledge, the learners' command of pronunciation (and also vocabulary and grammar) is more effectively tested within contexts of language performance.

According to the proponents of the approach, a rigorous implementation of the principles of CBLT both in language teaching and assessment will certainly and strongly enhance the learners' competencies in interaction, interpretation and production. Learners' pronunciation is supposed to be markedly improved after being exposed to seven years of instruction following this pedagogic innovation. The observed results, however, do not seem to confirm this claim. After more than a decade of its implementation in our context of English language teaching, it is high time to submit the competency-based approach experience in its entirety to a rigorous evaluation so as to propose research-based solutions to its weaknesses. The present study was designed to investigate the causes of the obtained disappointing outcomes as far as pronunciation is concerned.

\section{The Study}

The present study aimed at investigating the degree of compliance of middle and secondary school teachers' pronunciation teaching and assessment practices with the principles of the competencybased approach. In order to achieve this aim, two questionnaires have been designed and implemented to a sample of 87 middle and 62 secondary school teachers selected randomly on the basis of the principle of convenience. The sections of the two questionnaires have been designed so as to target the most important principles of the competency-based approach evoked above as far as the teaching and the testing of English pronunciation at the middle and secondary levels are concerned. In addition, and, as far as the issue of assessment is concerned, samples of BEM and BAC exams, on the one hand, and classroom tests and exams, on the other, have also been analysed and compared. 
3.1. The Compatibility of Teaching Practices with the Competency-based Approach

The degree of compatibility of the teachers' practices with the principles of the Competency-based Approach was investigated by highlighting the role assigned to pronunciation, the pronunciation content actually taught in the classrooms and the methodology adopted.

\subsubsection{The Role of Pronunciation}

The results show that many teachers assign a considerable role to pronunciation in their classes as almost all the teachers teach pronunciation in the English language classrooms. Overall, most of the teachers, except for 1st year middle school and 3rd year secondary school, devote reasonable time to pronunciation teaching, even though the time devoted to pronunciation differs from one teacher to another. The time, also, varies across the different levels. This implies that, except for 3rd year secondary school, the teachers emphasise pronunciation at all levels. A possible explanation might be the minimal attention assigned to pronunciation in the textbook designed for 3 rd year secondary school learners as compared with the other textbooks or by the fact that 3rd year middle school learners are expected to prepare for the Baccalaureate exam, which does not test the oral skills of speaking, listening and pronunciation.

Noticeable also is the fact that pronunciation is highly emphasised in 3rd and 4th year middle school as there were more teachers who reported that they often taught pronunciation $(41.97 \%$ in 3rd year middle school and $60 \%$ in 4 th year middle school) than those who reported that they sometimes taught it $(37.04 \%$ in 3 rd year middle school and $18.67 \%$ in 4 th year middle school). Furthermore, it has also been found that a number of teachers across the different levels usually (42.53\% of middle school teachers and $24.2 \%$ of secondary school teachers) or sometimes $(37.93 \%$ of middle school teachers and $37.1 \%$ of secondary school teachers) draw pupils' attention to aspects of pronunciation in other activities where the focus is not on pronunciation. In addition, some teachers reported also that they usually or sometimes taught pronunciation in reaction to error $(70.11 \%$ of middle school teachers and $51.61 \%$ of secondary school teachers).

These results clearly show that it is likely that pronunciation teaching is assigned some role in the classroom, which is in harmony 
with the fact that the English syllabuses and textbooks emphasise pronunciation teaching.

\subsubsection{Teaching the Pronunciation Content}

The results reveal that most of the teachers at all levels relied heavily on the textbooks in teaching pronunciation. This implies that the textbook is the only resource used by the teachers. As for the few teachers who answered negatively, they reported that they relied on other resources, the most important of which is the internet and some pronunciation books, and that they used other types of activities such as tongue twisters, songs and games. As regards the adaption of pronunciation activities in the textbooks, only a minority claimed that they did, especially when they found the activities too difficult for the learners, which is another evidence of the teachers' total reliance on the textbook.

Another interesting finding is that the teachers do not teach all the pronunciation activities but rather select some of them. The activities that are taught the least are the pre-communicative and the communicative activities and the ones involving phonetic symbols. By contrast, the teachers focus on awareness raising activities, especially the written ones which involve no oral production. These activities which make each pupil notice the pronunciation features individually take less time to be taught. For example, a considerable number of 1 st and 2 nd year middle school teachers reported that they taught all or most of the activities "Listen and Repeat" (the focus is on individual speech sounds, sound/ spelling relationship or word stress), "Identify" (the learners are given the opportunity to check their understanding of the pronunciation point taught) and "Compare" (the pronunciation points are further highlighted) while most teachers claimed teaching only some or none of the activities "Practise Stress and Intonation". The activities preferred by most of 3rd and 4th year middle school teachers are the activities which do not require the pupils to practice orally (Listen and answer the question or listen and do the exercise) as well as the activities involving discovering the rules (do the exercise and draw the rule). In addition a significant number of these teachers claimed that they taught only some or none of the activities requiring the pupils to practice either in a guided way or freely. 
Surprisingly, the results also reveal that not only are all the activities taught but also some pronunciation features are ignored by a significant number of teachers. The most important of these include intonation (for all levels though a number of secondary school teachers reported that while they taught some intonation lessons, they ignore others), sentence stress and aspects of connected speech.

All in all, these findings are a clear indication that there is a discrepancy between the principles of the competency-based approach to the presentation of pronunciation content in the textbooks and the teachers' real practices in the classroom. As a result, the students are deprived of the opportunity to practice and to consolidate the pronunciation points taught. Moreover, they are also deprived of learning other important points that are simply not emphasised or not taught at all by the teachers. Furthermore, the findings reveal that the teachers neither teach pronunciation for communication purposes nor do they follow a learner centred methodology.

\subsubsection{Teaching Methodology}

In a competency based language teaching model, the teachers' practices should reflect the main principles of the approach, namely individualised instruction/learner centredness, integration/ mobilisation and fostering learner autonomy.

\subsubsection{Individualised instruction/Learner Centredness}

Overall, the teachers' practices are not in line with individualised instruction, which is an important principle of the competency-based approach. First, the majority of teachers do not usually involve a considerable number of pupils in the pronunciation oral practice. Only $29.88 \%$ of middle school teachers and $19.36 \%$ of secondary school teachers claimed they usually did. This means that the learners lack enough opportunities to practice the pronunciation features taught. Second, the majority also reported that they did not assign pupils out-of-class pronunciation activities, aiming at fostering the elements taught in class or rarely did $(67.81 \%$ and $72.58 \%)$. Third, the method used by many teachers is monotonous. The majority of the middle and the secondary teachers always teach the same pronunciation activity in the same way and do not take the learners needs into consideration. There are even some teachers who admitted that they taught 
pronunciation depending on how the activity is instructed in the textbook, which means that they just follow the instruction verbatim. However, some teachers adjust their strategies to the learners' one. In other words, they teach the same pronunciation activity in different ways depending on the learners needs. Furthermore, while most of the teachers $(82.76 \%$ and $80.65 \%)$ reported that, when noticing that many pupils do not benefit from a pronunciation activity, they ignored the matter and moved on to the next point or taught the activity again and then moved on to the next point. The number of teachers claiming that they taught the activity until mastery is shown is very limited $(17.24 \%$ and $19.35 \%$ ). Moreover, the neglect of the suprasegmental features of intonation, sentence stress and aspects of connected speech suggests that instruction is not geared to the specific needs of Algerian learners.

\subsubsection{Integration/ Mobilisation}

The results show that the teachers do not frequently assess their pupils' ability to reinvest the previously taught pronunciation elements in their overall speech, including projects. This implies that they do not focus on whether the pupils integrate the pronunciation points taught earlier in subsequent lessons or not, which means that the pupils do not mobilise all the resources required to solve a task or a problem.

\subsubsection{Fostering Learner Autonomy}

The results reveal that in spite of the fact that a considerable number of teachers explain to pupils the importance of pronouncing correctly and encourage them to use multi-media outside the classroom to improve their pronunciation, not many teachers provide learners with strategies that help them self-notice, self-correct and most importantly, learn and improve pronunciation independently.

Two important strategies that are focused on in the present study are the use of phonetic notation and visual reinforcement. As for the former, while most of the teachers, except for 1st and 2nd year middle school, claimed that they encouraged their students to use pronunciation symbols to highlight some difficult pronunciations, the teachers' other practices differ from one level to another. Although there was not an agreement among the teachers of the different levels, most 1 st and 2 nd year secondary school teachers reported that they encouraged their students to read the phonetic transcriptions in their textbooks and in dictionaries. Moreover, Phonetic transcription, which is hardly ever used by 1 st and 2 nd year middle school teachers and rarely used by 3 rd year 
middle school and 3rd year secondary school teachers, is used by $72.13 \%$ of 1 st year secondary school teachers, $57.89 \%$ of 2 nd year secondary school teachers and by $46.66 \%$ of 4 th year middle school teachers. In addition, most of the teachers who claimed that they explained the usefulness of the phonetic symbols and phonetic transcription are 4th year middle school, 1st and 2nd year middle school teachers. Judging from these results, it seems that middle school teachers are against introducing the phonetic symbols and transcription in the first levels of instruction. In addition, it seems that the teachers are influenced by the content of the textbooks, which do not emphasise the use of the phonetic transcription. Contrary to the practices of the middle school teachers, secondary school teachers emphasise the use of phonetic transcription in the first two years but not in the final year. This can be justified by the fact that 3rd year secondary school teachers focus on preparing the learners for the BAC exam.

With regards to the use of visual reinforcement that might help the learners in learning and improving their pronunciation in an autonomous way, the results reveal that only some teachers highlight the pronunciation points on the blackboard, encourage their students to highlight the pronunciation points on their copybooks and draw the learners' attention to how the pronunciation aspects are highlighted in the textbooks. This suggests that most of the teachers do not emphasise the visual reinforcement of pronunciation points and so do not provide them with the ability to practise out of class.

3.2. The Compatibility of Assessment Practices with the Competency-based Approach

The main principles of the competency based approach with regards to assessment practices include diagnostic assessment and Formative assessment/Self-Assessment.

\subsubsection{Diagnostic Assessment}

Assessment of entering behaviour is an essential element of the teaching process and also one of the main principles of the competency based approach. In such an approach, the teacher should test the learners before instruction and should respond to the results of the pre-test. The results indicated that only $40.23 \%$ middle school teachers and $59.68 \%$ secondary school teachers claimed that they tested their pupils' pronunciation skills at the beginning of the school year, of which $62.86 \%$ middle school teachers and $51.35 \%$ secondary school teachers 
confirmed that they responded to the results of the pre-tests. Thus, it could be inferred from these results that one main principle of CBA is not implemented effectively in the classroom.

\subsubsection{Formative assessment/Self-Assessment}

The results revealed that most of the teachers do not regularly assess their students' understanding of the pronunciation points taught. In addition, only a few teachers claimed that they regularly corrected pronunciation errors while most of them chose the option "sometimes". The number of teachers who usually give scope for self-correction and peer-correction is also limited. This is another indication that the focus in pronunciation teaching is to cover the syllabus or to prepare for the official exams and not to improve the learners' pronunciation competency.

In addition, a solid majority of teachers admitted that they did not ask their students to fill in the grid or the questionnaire of each file/ unit that gives the learners the opportunity to assess their acquisitions. For example, only about $13 \%$ of teachers asked the pupils to do so in 3rd year middle school, 4th year middle school and 3rd year secondary school. In 2nd year secondary school and 1st year secondary school, more teachers $(21.05 \%$ and $29.51 \%$, respectively) claimed that they did. However, this implies that not only are the learners deprived from a very useful tool to become autonomous learners, but the teachers also skip a very necessary step that might help the learners recognize their weaknesses and to remedy them.

\subsubsection{Testing Pronunciation in CBLT}

In CBLT, the focus is on demonstrated performance and not merely on what the learners know about the language. That is why oral tests are the most appropriate and effective way to test pronunciation. According to the teachers' responses, not all the teachers test pronunciation as there are some teachers who answered negatively, especially in 2nd year secondary school (21.05\%) and 3rd year secondary school $(24.52 \%)$. In addition, only a very limited number of teachers (less than $8 \%$ for all levels) test pronunciation through oral tests while most of them use written activities which focus mainly on segmental elements ( for example, classify the words according to the vowel sound), word stress, number of syllables, pronunciation of final- 
$\mathrm{s}$ or final -ed. This implies that the teachers test the learners' phonological knowledge and not their actual pronunciation abilities.

3.3. The Relationship between the Teachers' Practices and Official Examinations

The relationship between the teachers' practices and the official examinations can only be investigated by analysing the pronunciation component in the $\mathrm{BEM} / \mathrm{BAC}$ examinations and in the class tests.

\subsubsection{Pronunciation in the BEM/BAC Examinations}

The formal /standardised/ summative tests are official exams designed by the ministry of education and conducted nationwide to test the learners' competencies at the end of the final year of the middle and the secondary cycle of the educational system. The two tests are called the BEM and the BAC examinations, respectively.

The analysis of $8 \mathrm{BEM}$ exams and $42 \mathrm{BAC}$ exams reveals that that the pronunciation component is present in the form of a written activity. The general coverage of the pronunciation component $(12.30 \%$ in BEM Exams and $9.01 \%$ in BAC exams) is a clear evidence that pronunciation is regarded as an important element by the test writers. This importance is also stressed in the marking system of the BEM Exams where $9.37 \%$ of the marks are devoted to pronunciation. However, the pronunciation component in the BAC exam with a percentage of $5.53 \%$ is less important.

As far as the pronunciation foci are concerned, the results reveal that all the activities included in the BEM exams emphasise only the segmental elements: vowels and diphthongs (50\%), pronunciation of final -ed (37.5\%) and silent letters (12.5\%). In like manner, the activities in the BAC exams, except for two about stress, also emphasise the segmental elements. The most frequently occurring aspects are the pronunciation of final-s with $(30.95 \%)$, pronunciation of final -ed (26.19\%) and the number of syllables in words (23.81\%). The remaining aspects, namely the silent letter, rhyme and stress are assessed three times or twice each. Therefore, the activities lack one major criterion of a good test, which is content validity. 
The examination of the pronunciation activities also shows that they test pronunciation knowledge. A striking feature emerging from the examination of the pronunciation activities in the BAC exams is that they do not differ from the ones included in the BEM exams in the sense that they are easy and highly susceptible to guessing.

Therefore, these types of activities do not measure the students' achievement in pronunciation after four years of instruction in the middle school and three additional years of instruction in the secondary school. A student who has a poor pronunciation can provide correct answers simply by guessing and a middle school learner can provide correct answers to the pronunciation activity in the BAC Exam as $\mathrm{s} / \mathrm{he}$ is familiar with the aspects tested. Thus, the activities also lack the criterion of discrimination.

Judging from this, and taking into account the written nature of the official exams, which ignores the oral skills, it is fair to say that not only is the students pronunciation performance not tested appropriately, but also the written pronunciation activity does not fulfil two major criteria of a good test, namely, discrimination and content validity. This suggests that the official exams might have a negative influence on the teachers' practices with regards to pronunciation teaching and testing.

\subsubsection{Pronunciation in the Class Tests}

Unlike the formal tests which are designed to test the learners competencies after three years (BAC exam) or four years of instruction (BEM exam), the class tests are conducted throughout an academic year not only to test the learners, but also to remedy their failure to achieve the expected competencies. In other words, they include both summative and formative tests. Class tests include three different types: diagnostic evaluation or test, while-in-term test and end -of-term test.

\subsubsection{Diagnostic Tests}

As stated earlier, diagnostic assessment is emphasised in the seven syllabuses. It follow, then, that, at the beginning of every school year, the teacher is required to diagnose the students speaking skills, including pronunciation. During the process of collecting tests, some teachers admitted that they did not conduct any diagnostic evaluation while others claimed that they just dealt with some revision activities which they wrote on the blackboard. The analyses of 15 diagnostic 
middle school tests (2nd year middle school, 3rd year middle school, 4th year middle school) and 15 secondary school tests (1st year secondary school, 2nd year secondary school, 3rd year secondary school) reveal that the teachers generally include some pronunciation activities despite the fact that the scope of activities is limited. In fact, the teachers' tests show how the format of the official BEM/ BAC tests has an influence on the construction of tests. Nevertheless, the goal behind carrying out the diagnostic evaluation and whether the teacher responds to the results of the diagnosis or not are considered more important than the diagnosis itself.

\subsubsection{While-in-Term Tests}

Like the official exams, the analysis of 120 middle school whilein-term tests (30 tests for each level) and 90 secondary school while-interm tests (30 tests for each level) reveals that the pronunciation component is present in the form of a written activity in most of the tests . Overall, the results show that, with the exception of 1 st year middle school with a percentage of $06.87 \%$, the pronunciation component plays an important role in middle and secondary school teachers' tests.

The results also show that while the activities emphasise only the segmental elements in the 1 st and 2 nd year middle school, they also test the suprasegmental elements in the other levels, though minimally in the 3rd and 4th years middle school. Moreover, it can be seen that the most frequently occurring aspects in the middle school tests are the vowels and diphthongs followed by pronunciation of final -ed. In 1 st year secondary school, the most frequently occurring aspect is phonetic transcription with a percentage of 41.67. Actually, the students are asked to decipher a sentence which is transcribed phonemically using the letters of the alphabet. Moreover, the number of syllables and stress are also emphasised with a percentage of $25 \%$ and $20.83 \%$ respectively while the aspect of the silent letters is the least frequent one with a percentage of $12.5 \%$. What is noticeable about these results is that the pronunciation of final-ed and final $-\mathrm{s}$ are not included at all in the analysed tests. In contrast to 1 st year secondary school, in the 2nd and 3rd years secondary school the pronunciation focus areas included in the while-in-term tests are the same areas included in the BAC exams, except for the inclusion of phonetic transcription in 2nd year secondary 
school. It is worth mentioning that in the activities where the same aspects included in the BEM or BAC exam are tested, the same instructions or directions are used.

\subsubsection{End-of- Term Tests}

The analysis of 120 end-of-term middle school tests and 90 secondary school tests also reveals that a pronunciation activity is present in section two, part one in most tests of the different levels. This clearly suggests that the pronunciation component has a role in teachers' tests. However, this importance varies from one level to another. Whereas pronunciation is tested minimally in 1 st year middle school $(06.32 \%)$ and 2 nd year middle school $(07.76 \%)$, pronunciation testing plays a significant role in 3rd year middle school (11.52\%), 4th year middle school (13.48\%) and 1 st year secondary school $(11.11 \%)$. Therefore, these results imply that the pronunciation component has a role in the teachers' end-of-term tests.

Another interesting finding is that that all the pronunciation activities included in the end-of-term middle school tests of the four levels test the segmental elements while the suprasegmental elements are totally absent. This implies that the teachers are influenced by the official BEM test, where the suprasegmental levels are not tested. The most frequently occurring aspects are the vowels and diphthongs and the pronunciation of final -ed. As regards the secondary school tests, the activities emphasise the segmental elements, but also test the suprasegmental elements, though minimally. The most frequently occurring aspect is the pronunciation of final $-\mathrm{s}$, followed by the number of syllables, the pronunciation of final -ed, the silent letters and word stress. It is worth noting that there are four activities focusing on phonetic symbols (03 in 1st year secondary school and 01 in 2 nd year secondary school), one activity on intonation (2nd year secondary school) and another on strong/ weak forms (3rd year secondary school).

Unlike the while- in-term tests in which teachers test some pronunciation aspects other than the ones included in the official BAC exam, the end-of-term tests constructed by the teachers are generally analogous to the BAC exams. Nonetheless, it is worth noting that apart from the pronunciation of final $-\mathrm{s}$, which was found as the most frequently occurring aspect in both the BAC tests and while-in-term tests, the other pronunciation aspects are ranked differently. 
Additionally, most of the activities are similar to the ones included in the BEM / BAC test. The same aspects are emphasised and the same instructions are used.

\subsubsection{Influence of Official Tests on Teacher's Instructional}

Practices

The nature of the official standardised tests (BEM and BAC), influences the teachers' instructional practices. In fact, these exams ignore the oral skills and, so, the learners' pronunciation. Despite the fact that these pronunciation activities are included in these test, they do not really test the learners' achievement in pronunciation because they are easy and highly susceptible to guessing. As a result, there is a tendency among the teachers to focus on the pronunciation areas that are generally tested (final-s with, final -ed, number of syllables, silent letters, word stress) and ignore the areas that are never included ( sentence stress and rhythm, intonation, strong and weak forms and aspects of connected speech).

The nature of the official tests also influences the teachers' assessment practices. First, only a very limited number of teachers test pronunciation through oral tests. Almost all teachers test pronunciation through written activities. Second, the teachers' tests include pronunciation activities that are very similar to the ones included in the official tests, either in terms of focus or type: the same aspects are emphasised and the same instructions are used.

\section{Conclusion}

The results of the present study have demonstrated that although some role is usually given to pronunciation inside the English language classroom, pronunciation teaching and assessment practices in the Algerian middle and secondary schools are not compatible with the principles of the competency-based approach. This discrepancy concerns practically all the defining features articulated by the approach: communication purposes, learner-centeredness, individualised instruction, learner autonomy, integration/mobilisation. As regards assessment, the discrepancy with the competency-based approach lies in the fact that the teachers do not assess their students' pronunciation 
skills on a regular basis and that they totally neglect the role of selfassessment. Another finding is that the teachers' inclination to prioritise the pronunciation features that are generally focused upon in the official tests has a negative influence on both the teaching and assessment practices. This anomalous situation does not only impact negatively on the effectiveness of pronunciation teaching, but it also deprives Algerian syllabus designers from the opportunity to evaluate the real strengths and weaknesses of this pedagogic innovation, and hence the ability to develop more adequate research-based local alternatives.

\section{References:}

Allison, D. (1999). Language Testing and Evaluation: An Introductory Course. Singapore University and World Scientific.

Ameziane, H., Hami, H. \& Louadji, K. (2005). At the Crossroads, Secondary Education/ Year One: Teacher's Book. Algiers: The National Authority for School Publications.

Beghoul,Y. (2007). The Phonological Interlanguage of the Undergraduate Students of English at the University of Constantine. Unpublished doctoral thesis. Mentouri University, Constantine.

Bowden, J. A. (2004). Competency-based learning. In Connotative Learning: The Trainer's Guide to Learning Theories and Their Practical Application to Training Design (pp. 91-100). Kendall Hunt Publishing.

Brinton, D. M. (2012). Pronunciation instruction. In A. Burns \& J. C. Richards (Eds.). The Cambridge Guide to Pedagogy and Practice in Second Language Teaching (pp. 246-257). Cambridge University Press.

Burgess, J. \& S. Spencer. (2000). Phonology and Pronunciation in Integrated Language Teaching and Teacher Education. System 28 (2), 191215.

Celce-Murcia, M. (1987). Teaching Pronunciation as Communication. In J Morley (ed.), Current Perspectives on Pronunciation. TESOL, Washington D. C.

Celce-Murcia, M., Brinton, D. M., \& Goodwin, J. M. (1996). Teaching Pronunciation: A Reference for Teachers of English to Speakers of Other Languages. Cambridge University Press.

Celce-Murcia, M., D.M. Brinton, J.M. Goodwin \& B. Griner. (2010). Teaching Pronunciation. A Course Book and Reference Guide. Cambridge University Press.

Council of Europe (2001). Common European Framework of Reference for Languages. Cambridge University Press. Press.

Dalton, C. \& B. Seidlhofer (1994). Pronunciation. Oxford University 
Derwing, T. M., \& Munro, M. J. (2005). Second language accent and pronunciation teaching: A research-based approach. TESOL Quarterly, 39(3), 379-397.

Graves, K. (2001). A Framework of Course Development Processes. In Hall, D.R. \& Hewings, A. (eds.) Innovation in English language teaching. London: Routledge

Harmer, J. (2001). The Practice of English Language Teaching. England: Longman.

Harris, R., Guthrie, H., Hobart, B. \& Lundberg, D. (1995) Competencybased Education and Training: between a Rock and a Whirlpool. Melbourne: Macmillan.

Jenkins, J. (2000). Phonology of English as an international language. Oxford University Press.

Jones, R. (1997). Beyond "listen and repeat": Pronunciation teaching materials and theories of second language acquisition. System, 25 (1): 103-112.

Kenworthy, J. (1987). Teaching English pronunciation. Harlow, U.K.: Longman

Knowles, G. (1995). Review of Approaches to Pronunciation Teaching. ELT Journal 49: 286-9

Ladefoged,P. (2001). A Course in Phonetics. New York: Harcourt, Brace, Jovanovich

Lenoir, Y. \& Jean, V. (2012). The Competency-Based Approach in African Textbooks. The New

Politics of the Textbook, 2, pp. 65-85

Morley, J. (1991). The Pronunciation Component in Teaching English to Speakers of

Other Languages. TESOL Quarterly 25 (3), 481-520.

Murphy, J. (1991). Oral Communication in TESOL: Integrating Speaking, Listening and Pronunciation. TESOL Quarterly, 25, 1, pp. 51-75.

Pennington,M. (1996). Phonology in English language teaching. Harlow: Addison Wesley.

Richards, J. C. (2015). Key Issues in Language Teaching. Cambridge University Press.

Richards, J. C., \&Rodgers, T. S. (2001). Approaches and Methods in Second Language Teaching. Cambridge University Press

Richards, J. C., \& Rodgers, T. S. (2014). Approaches and Methods in Language Teaching.

Cambridge: Cambridge University Press.

Roach,P . (2000). English Phonetics and Phonology: A practical course. Cambridge University Press.

Roegiers, X. \& De Ketele, J.-M. (2000). Une pédagogie de l'intégration. Bruxelles: De Boeck Université. 
Roegiers, X. (2010). La pédagogie de l'intégration. Bruxelles: De Boeck Université.

Rogerson-Revell, P. (2011). English Phonology and Pronunciation Teaching. Bloomsbury Academic.

Savage, L. (1993). Literacy through a Competency Based Education Approach. In Approaches to Adult ESL Literacy Instruction. Washington DC: Center for Applied Linguistics

Tardif, J. (2003). Développer un programme par compétences: de l'intention à la mise en œuvre. Pédagogie collégiale, 6(3), 36-44.

Tarone, E \& Yule, G. (1989). Focus on the language learner. Oxford University Press.

Tench,P. (1981). Pronunciation skills. Basingstoke: Macmillan. 